Reviews

"Social Influences upon the Household" or "Households and the Political Economy." The metaphor of "frontier" or "bonding" or "co-participation" could as well have served as "interface."

The ethnographic and archaeological papers in At the Interface are sturdy, mostly descriptive reports that can be read and utilized apart from the theoretical "spin." Regrettably, the volume lacks an index. To a considerable extent, the cases document the globalizing spread of world trade into exotic, backwater localities, and with it, the growth or accentuation of class differences, a raised standard of living, consumerism, and tendencies toward individualism. But the accounts also detail some of the limitless ways in which people adapt and accommodate; negotiate the obstacles and opportunities presented by the market and the state; and preserve or reconfigure their communities and their identities.

\title{
Spirit Wars: Native North American Religions in the Age of Nation Building, by Ronald Niezen, London and Los Angeles: University of California Press (2000), 256 pp.
}

\section{Reviewed by Stephen Greymorning, Departments of Anthropology and Native American Studies, University of Montana.}

In Spirit Wars, Ronald Niezen has masterfully researched the impact colonization has had on the religious practices of Indigenous North Americans. If influenced by initial appearances the book would appear overly ambitious, by its effort to address a multitude of events from a variety of geographic regions and time periods through subjects ranging from missionary and government intrusions to that of New Age mentalities. Solid research and scholarship, however, ground the book and give readers insight into a world of cultural domination and religious suppression rarely seen and most often misunderstood. Readers further benefit from several essays by Native contributors writing on how individual Native people and communities have been affected both historically and contemporarily by activities aimed at alienating Indigenous North Americans from their cultural ways of being.

Following his introductory chapter, Niezen sets about introducing readers to the rationale underlying early Spanish assaults on Native rituals and ceremonies; part of which included "making them amenable to White economic exploitation" (p. 39). Whether at the hands of missionaries or politicians, educating the "Indian" was a constant theme.

By the later part of the 1800s the marriage of evangelism and education became the modus operandi of the new Indian solution. In Chapter Three, Niezen exposes how the works of some of Europe's and America's greatest thinkers helped shape the world view of Anglo-Americans, which in turn yielded cultural forces that led a nation to believe it held a God-given right to shape a people in its own image. In one discussion Niezen holds the writings of Lewis Henry Morgan up as a mirror, reflecting the beliefs of a nation that perceived the best strategy for transforming Indian people's lives was through education and Christianity. The medium for this social experiment became the Indian residential schools, and the individual credited with bringing the needed structure to those schools was Lieutenant Richard Pratt.

From the onset the objective of the residential school was to convert Indians to White values. Niezen informs readers that Pratt believed the first step in this transformation was to physically change their appearance. While this had a devastating impact on many Indians, some also saw it as ludicrous.

When it was announced though [sic] an interpreter that their braids were to be shorn... Robert American Horse, made a speech... in which he concluded, "If I am to learn the ways of the White people, I can do it just as well with my hair on" (p. 62).

Most others, like Luther Standing Bear, were left feeling distraught. "After having my hair cut a new thought came into my head. I felt that I was no more Indian, but would be an imitation of a whiteman" (p. 63).

Thus after 200 years of failed missionary efforts to educate and assimilate Indians, Pratt's Indian residential school set the new standard. Niezen relates, however, that those standards brought with them the implementation of a level of punishment and control that became sadistic and often crossed over into the pathological. While it is common knowledge that Indians were punished for speaking their Native language, at the Alberni Indian residential school in Canada one individual revealed he was "punished for speaking Tseshalt by having sewing needles pushed 
Reviews

through his tongue. From then on he rejected his Native tongue and refused to teach it to his children" (p. 77). In almost all cases throughout North America, "the risk of excessive punishment, torture, or sexual abuse for Indian students... in residential schools was extremely high and had devastating and lasting consequences" (p. 77).

Niezen has made Spirit Wars significantly relevant by going beyond mere reporting. Spirit Wars probes some very difficult issues and brings with it a meaningful discussion of how, at least for Indians, the devaluing of selfworth, self-image or self-esteem, along with physical and substance abuse, can be linked to what is at times labeled as the "residential school syndrome." Certainly in my work I have repeatedly observed this residential school syndrome to be a significant factor in curtailing the progress of contemporary efforts to revitalize language in many Native American communities.

For most people, the idea that a war on Native spiritualism could continue in a contemporary and technologically advanced world would be quickly dismissed. In Niezen's chapter on medical evangelism, however, this idea receives persuasive support. Christianity and biomedicine, having long been wed, have also long been at war with shamans and native spirituality. This marriage, as warring companions, continues globally, impairing successful Native health practices such as ethnobotany and treating mental health afflictions. Niezen shows how this persistence, with its false sense of superiority, has failed Native communities. "If there is one major failing of biomedicine among Native Americans, it is in its delivery of mental health services" (p. 115). Drawing upon a 1990 report to Congress, Niezen relates that Native adolescents face 26.3 deaths per 100,000 population, when compared to 10.0 per 100,000 in the US general population. While for children between the ages of ten and fourteen, suicide deaths are four times higher than all races in America, in Canada "Indians are four to five times more likely to die from accidents or violence, and two to three times more likely to commit suicide" (p. 115).

Where missionaries were historically quick to point out the failings of Native medicinal knowledge, through Spirit Wars readers learn that Native people were not necessarily ignorant of Western medicine's limitations. To this regard Niezen draws on a collection of radio interviews conducted between 1992 and 1994 that dealt with the topic of healing. Through radio narratives and interviews, differences between Native and White perspectives and approaches in dealing with health issues are revealed. A common theme in these narratives is the inability of clinical doctors to bring about cures of chronic illnesses, and how when faced with such illnesses Native people tend to view the situation much differently. Niezen documented such a perspective from a Canadian radio narrative, in which the person interviewed reported, "She was alive, not dying like the doctor said... modern medicine failed, so I wasn't going to use anything modern" (p. 105).

A nice addition to this chapter is Phyllis Fast's article on "Gwich'in Athabascan Perceptions of Spirit Invasions and Recovery." Phyllis writes about two cases. In the first, a Gwich'in man was tormented by voices he heard in the house in which he lived. After running to his grandmother for help, she brought him to a minister to be exorcised. The man's mother, who owned the house, and who had also experienced supernatural occurrences while living in the house, burned it with all its contents to the ground so no one could ever be tormented again. Afterwards, the man was referred to a psychiatrist and was put on medication presumably for the remainder of his life. Phyllis goes on to discuss the differences between the medical, which looks at a psychological imbalance, a Christian, which looks at the devil as the cause, and the Gwich'in perspectives, which saw spirits in a specific locale as the cause.

The second case also dealt with a man hearing voices. With this one, however, his mother sought the guidance of Native health practitioners most commonly referred to as medicine men. In their diagnosis, one sees the sharp divergence in what Native and Western medicine would perceive and subsequently offer as a treatment. Native health practitioners diagnosed that he was hearing voices-thoughts of shamanic spirits because he himself was a latent shaman. His cure, or treatment, required him to be trained as a shaman. Here readers should not mistakenly believe that when individuals heard voices they were counseled to become a shaman. There was greater understanding and cultural flexibility than that.

What this chapter actually reveals is a cultural continuity that has persisted to present times. One disappointing aspect about this chapter comes from Niezen's use of the term biomedicine. By contrasting Native health practices with "biomedicine" as two distinct and separate systems, Niezen undermines huge contributions that medicine has received from the ethnobotanical knowledge of Indigenous peoples and fails to recognize that ethnobotany by its application is a form of biomedicine.

In the end, the chapter's message is fairly straightforward. Where Western medicine systematically seeks to alienate or isolate afflicted individuals, due to a perceived potential threat to the community, Native practices operate in such a way as to reincorporate the afflicted back into the community. As a result, Western medicine has failed Native people, when addressing certain Native health issues because the two approaches are culturally in conflict.

In Chapter Five, "The Politics of Repression," Niezen directly discusses government reaction to Indian

$100 \quad$ Vol. 82001

Journal of Political Ecology 
Reviews

spiritualism and religious ceremonies. On this same subject, Rupert Ross has observed that:

One of our first acts after contact was to outlaw the very mechanisms which permitted them [Indians] to cope with the traumas of life... Such practices as the pipe ceremonies, sweat-lodge ceremonies, shaking-tent ceremonies, sundances... we declared as heathen... The result was that a people about to face the most overwhelming social disintegration imaginable were left virtually defenceless against the anger, grief and sorrow that inevitably followed (Ross 1992: 143).

While Niezen's chapter agrees with Ross' claim, regarding the level of intolerance and contempt that government officials held for Native ceremonies, his section on the Ghost Dance runs into interpretive problems. By Niezen focussing primarily on how the Sioux interpreted Wavoka's message, readers are not made aware that the majority of tribes did not have the same interpretation. Niezen writes,

The Ghost Dance movement of 1890, which prophesised... an age when the dead would return, the whites would be eliminated in a cataclysm of selective destructiveness and the lives of all Indians would be returned to a state of bounty and pristine purity (p. 131).

What Niezen overlooked is that the destructiveness was to be selective for Indian and White alike. According to Porcupine, a Cheyenne emissary who heard Wavoka's teachings and witnessed his last miracle, Wavoka stated fighting was bad, "and we must all be friends with one another. He said the youth of all good people would be renewed...He told us not to quarrel or fight or strike each other, or shoot one another; that whites and Indians were to be all one people" (Peterson 1990: 108). For Wavoka, the all meant both Indian and Whites and anyone not following his teachings would perish. The Sioux, however, chose to bring away a different message. Another element overlooked is the fact that had Wavoka been preaching a message that all whites would be eliminated from the face of the earth, it is hardly likely that Bill Wilson, Wavoka's adopted white brother, would have helped Wavoka stage all his miracles.

At the time of Wavoka's messianic message, the Sioux, having been told they no longer possessed Paha Sapa and having been forced onto reservations, were experiencing significant hardship under United States government rule. They were desperate to put these insolent peoples in their place and restore balance to their lives. Though Wavoka had performed a number of seemingly miraculous feats, it was his last miracle that most impressed the Sioux and gave rise to the Ghost Dance Shirt and how the Sioux in particular interpreted the underlying message of the Ghost Dance religion.

Wavoka's Ghost Dance religion brought together Paiute, Christian, Shaker and Mormon religious elements. From the latter, Wavoka made use of the Mormon Endowment Robe, a robe "emblazoned with sacred symbols... reputed to protect the wearer from Satan and physical harm" (Peterson 1990: 110), and Sioux and Cheyenne emissaries were the first to see its power. In a staged miracle Bill Wilson, shot Wavoka at close range;

Many gasped in terror... Wavoka bent over as if struck by the blast, and buckshot spilled onto the blanket. But there was no blood. Screams and then excitement swept through the crowd as the prophet stood upright for all to see he was unharmed... Wavoka did not anticipate that the shirt would soon gain a reputation as a powerful protective shield (Peterson 1990: 110-111).

Sioux emissaries viewing this, saw in it their chance to reclaim what was rightfully theirs and possibly exact revenge in the process.

Niezen goes on in the chapter to offer solid analysis and discussion of Canada's repression of the potlatch, and America's attack on peyotism. With the latter Niezen further reveals the impact of Christianity's colonization of Native Americans with his disclosure of how peyote came under the assault of Christian Indians and purveyors of Indian religious traditions. There are many good aspects to this section, some of which discuss legal cases and how development issues have kept Native peoples under the influence of colonization. The chapter concludes with an enlightening essay from Valerie Long Lambert on the complexities of "Native Spiritual Traditions and the Tribal State." In this essay Lambert offers a critical analysis of Hollis Roberts' success in being elected, and several times reelected as Tribal Chair, on a political platform that exhibited strong hostility toward Native spirituality.

In Spirit War's last two chapters, Niezen addresses the role anthropology and museums has had on Native cultures in "The Collectors," and examines the paradoxical embrace of native spiritualism by followers of New Age philosophies in "Apostles of the New Age."

Since the time of initial contact Native religion and spirituality has been assaulted by the colonization efforts of Christian bearing cultures. In Chapter Seven, "Apostles of the New Age," Niezen provides detailed descriptions and analyses of the New Age movement. The chapter unfortunately can leave readers a bit confused as one easily sees a message that the New Age movement has shifted the battle on Native spirituality from assault to acclaim as a symbol of world salvation. Though Niezen's discussion attempts to move readers through the issues, with regard to this new phenomenon, there is concern that in the end readers are left confused. What is missing is a clear discussion 
Reviews

of why the Native community reacts toward charlatans, and that the surmounting level of appropriation that occurs by New Age activists only ensures that the spirit wars on Native North American religions will continue in the twenty-first century.

References Cited:

Peterson, Scott.

1990. Native American Prophecies: Examining the History, Wisdom and Startling Predictions of Ross, Rupert.

Visionary Native Americans. New York: Paragon House.

1992. Dancing with a Ghost: Exploring Indian Reality. Toronto: Reed.

Global Ethnography: Forces, Connections, and Imaginations in a Postmodern World. By Michael Burawoy, Joseph Blum, Sheba George, Zauzaa Gill, Teresa Gowan, Lynne Haney, Maren Klawiter, Steven Lopez, Sean O'Riain, Mille Thayer, eds. Berkeley: University of California Press (2000), 329 pp.

\section{Reviewed by Mary E. Hancock, Department of Anthropology, University of California, Santa Barbara.}

Global Ethnography, a volume that evolved from a graduate seminar at the University of California, Berkeley, is polished, smart, and energetic. The seminar-cum-working group was led by Burawoy, and sought to take on the thorny problem of how one might best engage globalization through ethnography without losing sight of either the sometimes concealed global forces and institutions that shape localities and the experiences of their inhabitants, or the individual experiences, narratives and situated knowledges that make up everyday lived experience. The result is a collection of individually authored articles that explore the articulations and disarticulations of global and local institutions, practices and ideas. In addition to providing historically and ethnographically rich descriptions, the articles serve as methodological examples of how one might study specific instances of the conditions and processes of globalization, along with its material and ideological effects.

The papers the volume comprises are clustered into three sections "Global Forces," "Global Connections," and "Global Imaginations," topics corresponding to the major heuristic categories developed by the group to analyze the varied encounters with globalization. Each major section is introduced with a brief discussion authored by those whose individual papers are included in that section. The articles are compelling and well-written - each one is based on serious and often prolonged ethnographic engagement. Four of the articles (those by Blum, George, Gilles, and Klawiter) are revised versions of papers that won national awards. All contributors write with an intensity that suggests deep intellectual and political commitment to their subjects.

The collection has both an "Introduction" and "Conclusion" by Burawoy. These chapters situate the volume in the larger trajectory of historically-informed ethnography influenced by the Chicago school of urban sociology and the Manchester school of extended case method. Burawoy charts his own intellectual/political genealogy in order to underscore how the boundaries of the nation-state, which implicitly framed most ethnographic endeavors of the twentieth century, are being challenged by the institutions and processes that are considered hallmarks of globalization. He does not, however, advocate the jettisoning of earlier approaches, rather he argues that their methods and theories can be mined and re-worked to yield new questions and explanatory paradigms. This ambitious goal is what Global Ethnography aims to accomplish and its contributions are significant and instructive.

Part One deals with the effects of global economic forces (global trade and governance measures administered by organizations such as WTO, World Bank as well as multinational economic ventures) on individuals and communities, charting the experience of downward mobility for working people in urban US (San Francisco) and Europe (Hungary). The three articles discuss welfare reform in post-socialist Hungary (Haney), the work of homeless recyclers in San Francisco (Gowan), and the fates of skilled shipyard laborers, also in San Francisco 